\title{
Academic Performance of Pre-Clinical and Clinical Medical Students' of East Coast Malaysian Peninsula: A Cross-Sectional and Descriptive Study That Stimulates Their Life
}

\author{
Rabiu Muazu Musa ${ }^{1}$, Mainul Haque ${ }^{2 *}$ \\ ${ }^{1}$ Faculty of Applied Social Sciences, Universiti Sultan Zainal Abidin, 21300, Terengganu, Malaysia. \\ ${ }^{2}$ Unit of Pharmacology, Faculty of Medicine and Defence Health, National Defence University of Malaysia, Kem Sungai Besi, Kuala Lumpur, Malaysia.
}

\begin{tabular}{|c|c|}
\hline ARTICLE INFO & ABSTRACT \\
\hline $\begin{array}{l}\text { Article history: } \\
\text { Received on: } 21 / 02 / 2017 \\
\text { Accepted on: } 12 / 04 / 2017 \\
\text { Available online: } 30 / 06 / 2017\end{array}$ & $\begin{array}{l}\text { The education of medical students is held in high esteem in any nation due to the greater responsibility the } \\
\text { profession is saddled with. Academic achievement of the students reflects their competency in their future } \\
\text { profession. Although the knowledge, skill and desired attitude of the students improve as they gain experience, } \\
\text { it is occasionally perceived that there is a dissimilarity in achievement because of diverse factors that impact on } \\
\text { the academic performance of the students. The present study }\end{array}$ \\
\hline $\begin{array}{l}\text { Key words: } \\
\text { Clinical Students, Pre- } \\
\text { Clinical Students, Academic } \\
\text { Performance, East Coast } \\
\text { Malaysian Medical Students, } \\
\text { Factors Affecting Academic } \\
\text { Performance. }\end{array}$ & $\begin{array}{l}\text { pre-clinical East Coast Malaysian medical students' academic performance. A self-reported questionnaire which } \\
\text { assesses various factors potentially affecting the academic performances of medical students was administered } \\
\text { to a total of } 232 \text { students of both clinical and pre-clinical years, and Multivariate analysis of variance } \\
\text { (MANOVA) was used in this study to analyze the data gathered. The study results found no significance } \\
\text { difference in the GPA scores amongst gender and marital status across all the students, } P>0.05 \text {. A statistically } \\
\text { significant difference in GPA scores was found between the clinical and pre-clinical students } P<0.001 \text {. } \\
\text { However, on various factors affecting students' performance, only family income and favoring particular place } \\
\text { while reading were discovered to have significant effects on the students' performance } P<0.05 \text { while other } \\
\text { factors did not vary between the groups } P>0.05 \text {. The results from the current study might be beneficial to the } \\
\text { students by allowing them to comprehend better the factors that can affect their academic performance. }\end{array}$ \\
\hline
\end{tabular}

\section{INTRODUCTION}

Students are the key resources of any nation. The students' performance shoulders a vital part in delivering best quality graduates who will become great leaders and manpower for the nation by taken charge of the nation's financial and social advancement. Academic accomplishment is one of the key elements considered by any sector in recruiting workers, particularly for the new graduates. Accordingly, students need to put the best effort in their study to get good grades and to prepare

\footnotetext{
* Corresponding Author

Mainul Haque, Professor, Unit of Pharmacology, Faculty of Medicine and Defence Health, National Defence University of Malaysia, Kem Sungai Besi, 57000 Kuala Lumpur, Malaysia.

Email: runurono@gmail.com
}

themselves for future opportunities in their profession and consequently to fulfill their respective job's demand (Chiu et al., 2015). The higher education performance relies on the academic performance of graduate students. In another perspective (Bratti and Staffolani, 2002) witnessed that the extent of student's prior educational performance and results is the most imperative gauges of students forthcoming accomplishment; this alludes the higher the past results, the better will the student's academic performance tend to be in future endeavors. However, another study (Rippey, et al., 1981) revealed that a student who is successful in his preferred career possesses good study habits. The students are identified as good planners for their study time and as such the students apply these practices to all their classes. A study on the financial status of students and established that the socio-economic background has a significant influence on student's educational representation 
(McMillan and Western, 2000). The researchers stressed further that poor socio-economic background had been the primary birthplace of educational discrepancy among students and students' academic attainment. Similarly, reported that parents or guardians who have social, educational and economic privileged circumstances positively strengthen the level of their child's success in future (Considine and Zappala, 2002).

It has been shown in computer science related courses, that parental need as well as understanding from the parents to engage them would most likely influence the students to attempts to respond positively to the teaching-learning progression and as such have a positive impact on their total educational consequence (Goddard, 2003). Parents' involvement has been characterized and measured in different ways, including activities that parents participate in at home and at school as well as positive attitudes parents have towards education. Several studies indicated that lack of support and encouragement could result in poor academic achievements, lack of interest and subsequently lead to the withdrawal of the students (Schlee et al., 2009; Abar et al., 2009; Rubin et al., 2009; Legault et al., 2006; Lacour and Tissington, 2011).

A medical undergraduate's educational achievement takes the concern of all the stakeholders directly or indirectly linked to medical education. The greater number of medical school stakeholders are cautious about students' accomplishments as it depicts their diverse fields of endeavours. The education of medical students is held in high esteem in the nation because of the greater responsibility the profession is saddled with. It has been pointed out that the health of a nation is congruent with the performance of its medical team and hence, the academic excellence of medical students is vital for a healthy society (Nourian et al., 2008).

There are numerous factors affecting a student's academic performance as shown by the previous evidence above; these factors are the potential indicators as well as forecasters of accomplishment after or before prerequisite qualification to medical school.

The current study intended to explore various factors affecting Malaysian medical students' of Universiti Sultan Zainal Abidin (UniSZA) academic performance and to determine the differences in these factors between clinical and pre-clinical students on basis of pre-university and post-university grade point average (GPA) scores.

\section{MATERIALS AND METHODS}

The present study was a cross-regional research carried on medical students of Year I to V of academic session 2014/2015 of the faculty of Medicine, UniSZA, Terengganu, Malaysia. The universal sampling was adopted as the total population was only 300. Study Participants: The participants of the study comprised both clinical and pre-clinical students drawn from east coast Malaysia. The participants were medical students from different states on the east coast of Malaysia. Research Instrument: The instrument for the present study was chosen, transformed, and validated from the preceding study (Al Shawwa et al., 2015). The formal approval was received to utilizing the questionnaire from Dr. Ahmad A. Abulaban, Department of Medicine-Neurology, King Fahad National Guard Hospital, King Abdul-Aziz Medical City, PO Box 377033, Riyadh 11335, Kingdom of Saudi Arabia. Despite the prior validation of the questionnaire by the previous researchers, the questionnaire was further pretested and validated for the medical students of UniSZA in this study.

Ten medical students of the faculty of medicine, UniSZA ( 2 from each year) engaged for the pretested program. Obviously, these students did not participate in the main study. As no change was required precisely the same questionnaire was maintained as of King Abdul Aziz University to conduct the study after revalidation in UniSZA (Al Shawwa et al., 2015). This questionnaire contains total 36 questions. Almost all questions were close-ended. Only socio-demographic section was modified in the mentioned questionnaire. Greatest components of this instrument indicated satisfactory values, with a range between 0.672 and 0.882 , which revealed that both instruments contained acceptable internal consistency and reliability.

The confirmation of concurrent validity was made clear by the significant relationships between the components of each section and the overall mean ( $\mathrm{rs}=0.332-0.718 ; P<0.05$ ) in each section (Nunnally, 1978; Barman et al., 2012). Data Set: Similar raw data set were utilized for another study in other perspectives (Haque et al., 2016). Study Period: The period of study was September 2015. Statistical Analysis: Multivariate analysis of variance (MANOVA) was applied in this study to analyze the data gathered. The clinical years (level of the students) and GPA of the students were used as the dependent variables (DV) while, the responses of the students on the various factors influencing their academic performances were used as the independent variables (IVs).

All the statistical analysis was conducted at a confidence level of $\mathrm{p} \leq 0.05$ using SPSS version 21 for windows (IBM Corporation, Armonk, NY). Ethical Approval: Investigative standards were rigidly preserved, primarily concerning confidentiality.

Moreover, this study was undisclosed, participation was optional, and written informed consent was received before data uptake process was instituted. This study received the endorsement of ethical approval from UniSZA Research Ethics Committee (UHREC) [UniSZA, C/1/UHREC/628-1 (5), March 12, 2015].

\section{RESULTS}

The descriptive statistics of the dependent variables, independent variables, marital status (Figure 1), gender (Figure 2), study level of the students, mean, standard deviations number of observations in each category are portrayed in Table 1. It can be observed that a total number of 232 students participated in the survey. However, only a total number of 170 clinical students and 50 pre-clinical students completed the survey instrument. 


\section{Marital Status of the students}

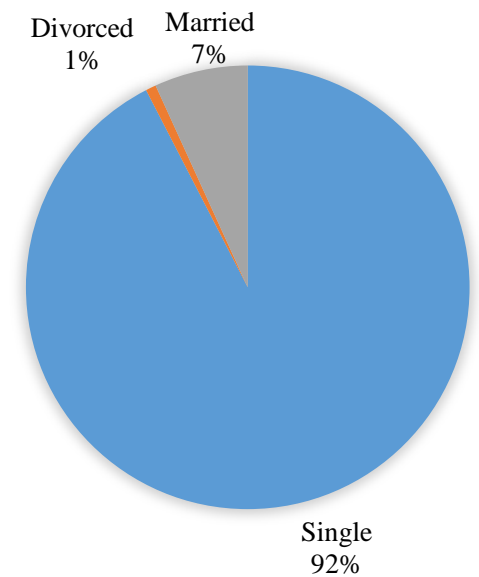

Fig. 1: Marital Status Percentage Representation of the Students.

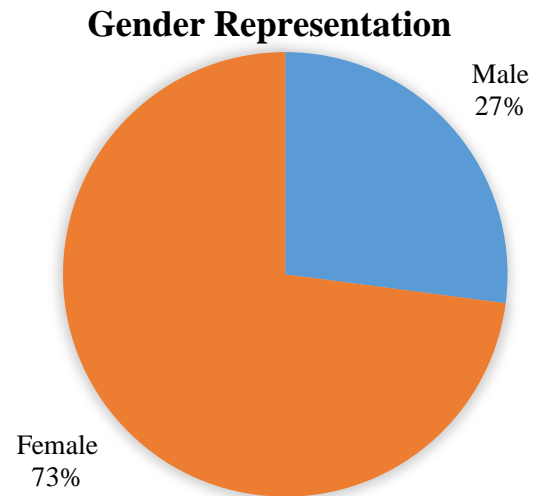

Fig. 2: Gender Percentage Representation of the Students.

Table 1: Descriptive statistics of the measured variables.

\begin{tabular}{ccccc}
\hline D. Variables & In. Variables & Mean & Stand D. & N \\
\hline Status & Single & 1.7 & 0.4 & 122 \\
& Married & 1.6 & 0.6 & 9 \\
& Divorced & 1.0 & 0.0 & 1 \\
& Total & 1.7 & 0.5 & 232 \\
\hline Gender & Male & 1.3 & 0.7 & 62 \\
& Female & 1.5 & 0.9 & 167 \\
& Total & 1.5 & 0.9 & 229 \\
\hline Years & Clinical & 3.9 & 0.1 & 170 \\
& Pre-clinical & 3.9 & 0.1 & 50 \\
& Total & 7.8 & 0.1 & 220 \\
\hline
\end{tabular}

Table 2: Comparison of GPA versus status and gender of the students.

\begin{tabular}{cccccc}
\hline GPA Vs. Status & \multirow{2}{*}{ Pillai's Trace } & DF & Error & F & Sig \\
\cline { 3 - 6 } & & 6.00 & 249.00 & 1.17 & 0.32 \\
GPA Vs. Genders & & 24.00 & 278.00 & 0.92 & 0.58 \\
\hline
\end{tabular}

The inferential statistics of the comparisons of GPA scores on gender and marital status of both clinical and pre clinical students (Table 2). It can be observed from the table that there is no statistically significant difference in the GPA scores between gender and marital status across all the students, $P>0.05$.
The inferential statistics of GPA scores and pairwise comparison between Post-University \& Pre-University Year students. It can be observed that there is statistically significant difference in GPA scores between the students $P<0.001$ (Table $3 \&$ Figure 3 ).

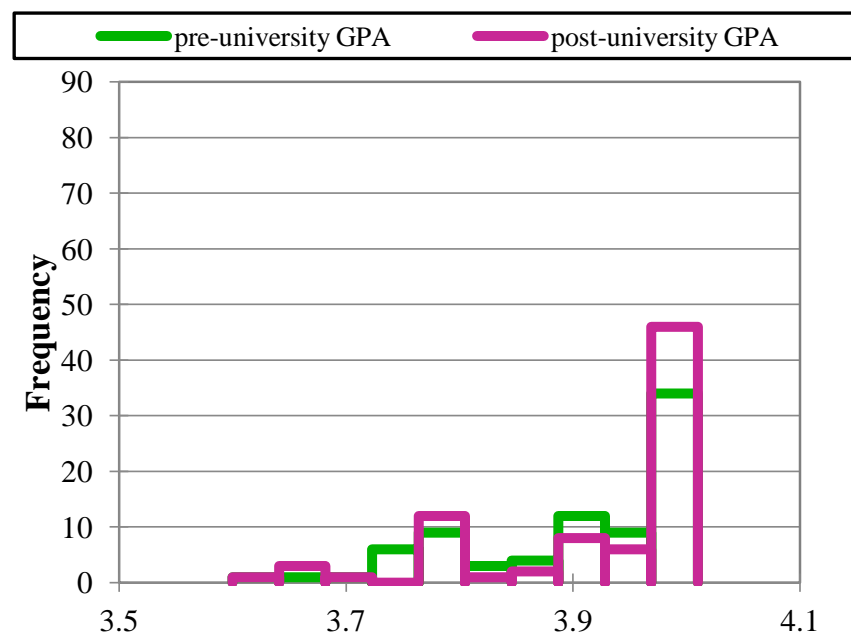

GPA Scores Distribution

Fig. 3: Comparison of GPA Scores distribution between the Post and PreUniversity students

However, a follow-up pair-wise comparison revealed that the GPA scores of Post-University students are higher than PreUniversity Year students' $P<0.001$. The social and economic aspects on the performance of the students. It can be observed from the table that, social and economic factors specifically several families, living with family, family problems, students' income, responsible financially, transport, sharing transport, responsible for driving others and responsible for doing household chores have no significant influence on the students' performance $P>0.05$. However, family income is found to have significant effects on the students' performance $P<0.05$ (Table 4).

The social and lifestyle characteristics on performance of the undergraduates. It can be seen from the table that none of the factors significantly affect the performance of the student's $P>0.05$. Moreover, the clinical students are more likely to spend their time more on movies and music, social life, and co-curricular activities compared to pre-clinical students due to the higher means recorded on these factors among the clinical students. In another hand, pre-clinical students are more likely to spend hours online not related to college, smoking, conferences and are most critical about time spent on the hobby as their means of these factors are higher. No much difference on their means regarding consumption of caffeinated beverages (Table 5).

The reading styles on the performances of the students. The table reveals that there is no statistical significance difference between the reading styles of both clinical and pre-clinical students on their academic performance $P>0.05$. 
Table 3: GPA scores comparison between post-university \& pre-university year students.

\begin{tabular}{|c|c|c|c|c|}
\hline GPA Vs. Post-University \& Pre-University Year & $\mathrm{DF}$ & MS & $\mathrm{F}$ & Sig \\
\hline \multirow{3}{*}{ Pairwise Comparison } & 2 & 0.81 & 8.027 & $0.000 *$ \\
\hline & Clinical Years & M DIFF(1-J) & SE & $P$ \\
\hline & Post-University \& Pre-University Year & $0.72 *$ & 0.18 & $0.000 *$ \\
\hline
\end{tabular}

*Significant at $P<0.001$ Post-University \& Pre-University Year

Table 4: Social and economic factors on performance of the students.

\begin{tabular}{|c|c|c|c|c|}
\hline Social and Economic Factors & Clinical Students N= 113 M(SD) & Pre-Clinical N= 29 M(SD) & Total & 95\% CI ( $P$ value $)$ \\
\hline Number of Family Member & $6.16(0.171)$ & $6.17(0.337)$ & 142 & $6.67(0.496)$ \\
\hline Live with Family & $0.74(0.043)$ & $0.552(0.085)$ & 142 & $1.07(0.131)$ \\
\hline Family Problems & $0.35(0.092)$ & $0.586(0.182)$ & 142 & $0.974(0.484)$ \\
\hline Family Income & $1.26(0.061)$ & $1.66(0.120)$ & 142 & $1.74(0.012 *)$ \\
\hline Students Income & $1.04(0.058)$ & $0.97(0.115)$ & 142 & $1.42(0.829)$ \\
\hline Responsible Financially & $0.062(0.022)$ & $0.034(0.043)$ & 142 & $0.188(0.826)$ \\
\hline Transport & $3.74(0.116)$ & $3.48(0.229)$ & 142 & $4.57(0.580)$ \\
\hline Share Transport & $0.37(0.046)$ & $0.48(0.091)$ & 142 & $0.615(0.403)$ \\
\hline Responsible to Drive Others & $0.43(0.068)$ & $0.35(1.33)$ & 142 & $0.740(0.738)$ \\
\hline Responsible to do House Chores & $0.58(0.046)$ & $0.66(0.092)$ & 142 & $0.745(0.381)$ \\
\hline
\end{tabular}

*Significant at $P<0.05$.

Table 5: Social and lifestyle characteristics on performance of the students.

\begin{tabular}{|c|c|c|c|c|}
\hline Social and Lifestyle Characteristics & Clinical Students N= $161 \mathrm{M}(\mathrm{SD})$ & Pre-Clinical $\mathrm{N}=48 \mathrm{M}(\mathrm{SD})$ & Total & 95\% CI ( $P$ value $)$ \\
\hline Hours Spent on Movies \& Music & $1.27(0.075)$ & $1.15(0.137)$ & 209 & $2.11(0.540)$ \\
\hline Hours Spent Online Not Related to College & $1.44(0.061)$ & $1.46(0.112)$ & 209 & $1.46(0.181)$ \\
\hline Most Accurate About Time Spent on Hobby & $1.57(0.067)$ & $1.67(0.123)$ & 209 & $1.98(0.624)$ \\
\hline Smoking & $0.03(0.014)$ & $1.69(0.026)$ & 209 & $0.13(0.579)$ \\
\hline Consume Caffeinated Beverages & $0.64(0.054)$ & $0.65(0.099)$ & 209 & $0.89(0.649)$ \\
\hline Social Life & $2.01(0.080)$ & $1.81(0.147)$ & 209 & $2.65(0.785)$ \\
\hline Cocurricular Activity & $2.81(0.070)$ & $2.48(0.129)$ & 209 & $3.36(0.081)$ \\
\hline Conference & $1.07(0.047)$ & $1.13(0.086)$ & 209 & $1.71(0.262)$ \\
\hline After Univ Hrs. & $1.15(0.031)$ & $1.25(0.057)$ & 209 & $1.74(0.064)$ \\
\hline
\end{tabular}

Abbreviations: $\mathrm{M}=$ mean, $\mathrm{SD}=$ Standard deviation, $\mathrm{CI}=$ Confidence interval.

Table 6: Reading styles and performance of the students.

\begin{tabular}{|c|c|c|c|c|}
\hline Reading styles & Clinical Students $\mathrm{N}=170 \mathrm{M}(\mathrm{SD})$ & Pre-Clinical $\mathrm{N}=49 \mathrm{M}(\mathrm{SD})$ & Total & $95 \% \mathrm{CI}(P$ value $)$ \\
\hline Mapping & $0.19(0.031)$ & $0.20(0.057)$ & 219 & $0.25(0.876)$ \\
\hline Note-Forming & $0.42(0.038)$ & $0.47(0.071)$ & 219 & $0.49(0.423)$ \\
\hline Highlighting & $0.64(0.037)$ & $0.64(0.069)$ & 219 & $0.81(0.675)$ \\
\hline Summarizing & $0.30(0.035)$ & $0.29(0.066)$ & 219 & $0.37(0.307)$ \\
\hline Recording & $0.02(0.014)$ & $0.08(0.027)$ & 219 & $0.13(0.159)$ \\
\hline Reading-Loud & $0.19(0.031)$ & $0.20(0.057)$ & 219 & $0.32(0.876)$ \\
\hline Reading-Silent & $0.26(0.033)$ & $0.20(0.062)$ & 219 & $0.33(0.628)$ \\
\hline Start by Reading Then Memorizing & $0.45(0.038)$ & $0.43(0.071)$ & 219 & $0.57(0.641)$ \\
\hline Start by Memorizing & $0.08(0.022)$ & $0.10(0.040)$ & 219 & $0.18(0.870)$ \\
\hline
\end{tabular}

However, their comparative mean scores on each reading style have indicated that pre-clinical students are more likely to engage in mapping, note forming, highlighting, recording, reading aloud and start by memorizing while the clinical students are more likely to employ summarizing, read silently as well as start by reading than memorizing (Table 6). The comparative analysis of attendance styles of both clinical and pre-clinical students. The table demonstrates that there is no statistically significant difference between the students on the attendance from the variables $P>0.05$. Nonetheless, the corresponding mean scores reveal that clinical students are more likely to attend tutorials and clinical sessions while pre-clinical students are more apt to attend lectures, practicals, and PBL (Table 7). The comparisons of reading behaviors on the performance of the students. It can be observed that there is no statistically significant difference between reading behaviors styles such as ensuring silence/no interruption, favor certain body position while reading, listening to Qur'an/music/TV, start reading for next year, having clinical training, conducting research, enjoying vacation and preparing for exams among both clinical and pre-clinical students $P>0.05$ (Table 8). However, a significant difference is found among the students on favoring certain place while reading which suggested that favoring certain place while reading significantly affects the performance of the students' $P<0.05$ (Table 8). 
Table 7: Attendance styles on the performance of students.

\begin{tabular}{|c|c|c|c|c|}
\hline Attendance Styles & Clinical Students N=160 M(SD) & Pre-Clinical N= 43 M(SD) & Total & $95 \%$ CI ( $P$ value $)$ \\
\hline Lectures & $1.09(0.024)$ & $1.09(0.046)$ & 203 & $1.14(0.953)$ \\
\hline Tutorials & $1.10(0.024)$ & $1.05(0.046)$ & 203 & $1.15(0.563)$ \\
\hline Practicals & $1.11(0.031)$ & $1.21(0.046)$ & 203 & $1.33(0.340)$ \\
\hline PBL & $1.08(0.033)$ & $1.12(0.063)$ & 203 & $1.15(0.886)$ \\
\hline Clinical & $1.22(0.060)$ & $1.19(0.115)$ & 203 & $1.34(0.931)$ \\
\hline
\end{tabular}

Table 8: Reading behaviour on the performance of the students.

\begin{tabular}{|c|c|c|c|c|}
\hline Reading Behavior & Clinical Students N=170 M(SD) & Pre-Clinical $\mathrm{N}=49 \mathrm{M}(\mathrm{SD})$ & Total & 95\% CI (P value) \\
\hline Ensure Silence / No Interruptions & $0.54(0.038)$ & $0.45(0.072)$ & 219 & $0.61(0.359)$ \\
\hline Favor Certain Place & $0.38(0.037)$ & $0.61(0.070)$ & 219 & $0.75(0.008 *)$ \\
\hline Favor Certain Body Position & $0.22(0.032)$ & $0.22(0.059)$ & 219 & $0.34(0.866)$ \\
\hline Listen to Qur'an / Music / TV & $0.28(0.035)$ & $0.33(0.065)$ & 219 & $0.46(0.683)$ \\
\hline Start Reading for Next Year & $0.18(0.028)$ & $0.10(0.053)$ & 219 & $0.24(0.373)$ \\
\hline Have Clinical Training & $0.04(0.010)$ & $0.12(0.034)$ & 219 & $0.19(0.102)$ \\
\hline Conduct Research & $0.02(0.010)$ & $0.02(0.019)$ & 219 & $0.06(0.983)$ \\
\hline Enjoy My Vacation & $0.90(0.022)$ & $0.94(0.041)$ & 219 & $1.02(0.676)$ \\
\hline Preparing for Exam & $1.88(0.058)$ & $1.84(0.108)$ & 219 & $2.05(0.920)$ \\
\hline
\end{tabular}

*Significant at $P<0.05$.

\section{DISCUSSION}

The current research was conducted to discover various elements that stimulus East Coast Malaysian medical students' academic performance and to determine the differences in these factors between clinical and pre-clinical students. The findings based on the marital status and gender categories revealed that there is no significance difference between gender and marital status on the GPA scores $P>0.05$ (Table 2). This finding has indicated that both gender and marital status could not differentiate the students on their GPA scores. This might be explained that gender and marital status not have straight forward effect on students' motivation, free time for studying and efficacy of their learning practice. Despite the fact that, this finding has contravened the previous finding from a study in Saudi Arabia which reported higher academic performance among female and married students. Nonetheless, their study was conducted on medical students who were particularly in their preclinical year (Salem et al., 2013).

The GPA scores comparison between clinical and preclinical students' shows that the GPA scores of clinical students are higher than pre-clinical students' $P<0.001$ (Table 3). This is not surprising since the medical students are better groomed and that enable them to employ different techniques and preparation for both their classes and exams as opposed to the pre-clinical students who are only at their preparatory stage. The results on the social and economic factors on the achievement of the students showed that number of families, living with family, family problems, students' income, responsible financially, transport, sharing transport, responsible for driving others and responsible for doing household chores have no significant influence on the students' performance $P>0.05$. However, family income is found to have significant effects on the students' performance $P<0.05$ (Table 4). The most prevailing assertion is that the financial position of parents regulates the nature of their children academic achievement. Another research reported that the low financial status has an adverse impact on the academic performance of students since the necessary requirements of the students stay exasperated and consequently reduce their performance academically (Farooq et al., 2011). Additional survey documented that students' academic accomplishment and activities, awareness of their coping styles and positive attributions as well as background features (i.e., family income, parents' level of education, living with family, family problems, students' income, responsible financially, transport, etc.) were indirectly connected to their composite scores, through academic attainment in high school (Ferguson et al., 2002). The students experience a number of difficulties in forming effective study attitudes and study habits. Family income is a media through which a student can support the academic needs, develop study manners and study habits and is instantaneously corresponding to academic success. The students who are from higher income family may likely perform well in the exams.

The findings on the social and lifestyle characteristics on performance of the students demonstrated that hours spent on movies \& music, hours spent online not related to college, most accurate about time spent on hobby, smoking, consume caffeinated beverages, social life, cocurricular, conference and reading after universities hours did not significantly differ between the clinical and pre-clinical students $P>0.05$ (Table 5). Nonetheless, the clinical students are more likely to spend their time more on movies and music, social life, and co-curricular activities compared to pre-clinical students due to the higher means recorded on these factors among the clinical students. In another hand, preclinical students are more likely to spend hours online not related to college, smoking, conferences and are most critical about time spent on the hobby as their means of these factors are higher. No much difference between their means regarding consumption of caffeinated beverages. This finding agrees with the finding of an earlier study (Al Shawwa et al., 2015) who revealed that factors such as expending time watching television and listening to music had no substantial difference amongst medical students of higher 
and lower GPA scores. However, distinctions were found in time dedicated to different forms of social networking between the groups which might likely have a substantial difference on the student's achievement.

On the reading styles and performance of the students, the findings indicated that the various reading styles used by the students namely; mapping, note-forming, highlighting, summarizing, recording, reading-loud, reading-silent, start by reading then memorizing, start by memorizing did not significantly differ among the students $P>0.05$ (Table 6). However, their comparative mean scores on each reading style have indicated that pre-clinical students are more likely to engage in mapping, note forming, highlighting, recording, reading aloud and start by memorizing while the clinical students are more likely to employ summarizing, read silently as well as start by reading than memorizing. This discovery is in concord with the results of the previous researchers who observed no significant difference between different reading styles employed by the medical students on their academic performance (Al Shawwa et al., 2015).

Concerning the attendance styles on the performance of the students, the attendance of lectures tutorials, practicals, PBL and clinical classless exhibited no statistically significant difference between the clinical and pre-clinical students' $P>0.05$ (Table 8). Nevertheless, the corresponding mean scores reveal that clinical students are more likely to attend tutorials and clinical sessions while pre-clinical students are more apt to attend lectures, practicals, and PBL. This finding replicated the findings of earlier studies documented that higher participation of PBL among students of greater GPA scores and indicated that problemcentered discourse inspires greater absorption of fresh information in the student's existing knowledge base, carrying out the ensuing information more approachable and remembered easily (De Grave et al., 2001; Al Shawwa et al., 2015).

The findings on the reading behavior on the performance of the students revealed that there is no statistically important variation between reading behaviors styles such as ensuring silence/no interruption, favor certain body position while reading, listening to Qur'an/music/TV, start reading for next year, having clinical training, conducting research, enjoying vacation and preparing for exams among both clinical and pre-clinical students $P>0.05$. However, a significant difference is found among the students on favoring certain place while reading which suggested that favoring certain place while reading significantly affects the performance of the students' $P<0.05$. This finding is congruent with a study revealed that most the students with higher GPA characteristically study alone in an isolated prepared place (Al Shawwa et al., 2015). It could, therefore, be deduced that the relationship between traits disposition, home background elements and their impact on educational achievement is a varied process. There exist numerous variables covered, and conclusion cannot be readily made. Academic achievement is not attained by a particular learning strategy; "good learners" function productively in very distinct but special manners. This discovery might point out that the overall effectiveness of group studying is lower than studying individually.

\section{CONCLUSION}

Analysis of the results of present study revealed the following findings (1) there is no significant difference in the GPA scores between gender and marital status across all the students (2) the clinical students have higher academic achievement compared to pre-clinical students (3) social and economic factors such as number of families, living with family, family problems, students income, responsible financially, transport, sharing transport, responsible to drive others and responsible to do household chores have no significant influence on the students' performance. However, family income is shown to have substantial effects on the students' performance (4) social and lifestyle characteristics on performance of the students demonstrated that hours spent on movies \& music, hours spent online not related to college, most accurate about time spent on hobby, smoking, consume caffeinated beverages, social life, cocurricular, conference and reading after universities hours did not significantly differ between the clinical and pre-clinical students (5) the various reading styles used by the students indicated that pre-clinical students are more likely to engage in mapping, note forming, highlighting, recording, reading aloud and start by memorising while the clinical students are more apt to employ summarising, read silently as well as start by reading than memorising (6) the clinical students are more likely to spend their time more on movies and music, social life, and cocurricular activities compared to pre-clinical students while, pre-clinical students are more likely to spend hours online not related to college, smoking, conferences and are most critical about time spent on hobby as their means of these factors are higher (7) favouring certain place while reading significantly affects the performance of the students (8) clinical students are more likely to attend tutorials and clinical sessions while preclinical students are more apt to attend lectures, practicals, and PBL.

Based on the current findings, it was concluded that several factors pose a high influence on the academic achievement of the medical student and therefore, to achieve a greater level of academic performance a variety of strategies need to be harnessed by a medical student.

\section{ACKNOWLEDGEMENT}

Authors are grateful to those medical students of UniSZA, who had participated in the current study. The authors are also obliged to Dr. Ahmad A. Abulaban, Department of Medicine-Neurology, King Fahad National Guard Hospital, King Abdul-Aziz Medical City, PO Box 377033, Riyadh 11335, Kingdom of Saudi Arabia, for providing permission to use his questionnaire for this study. The authors also like to extend their heartfelt thanks to all members of the Universiti Sultan Zainal Abidin Research Ethics Committee. 
Financial support and sponsorship: Nil.

Conflict of Interests: There are no conflicts of interest.

\section{REFERENCES}

Abar B, Carter KL, Winsler A. The effects of maternal parenting style and religious commitment on self-regulation, academic achievement, and risk behavior among African-American parochial college $\quad$ students. J $\quad$ Adolesc, 2009; 32: 259-273. http://dx.doi:10.1016/j.adolescence.2008.03.008

Al Shawwa L, Abulaban AA, Abulaban AA, Merdad A, Baghlaf S, Algethami A, Abu-Shanab J, Balkhoyor A. Factors potentially influencing academic performance among medical students. Adv Med Educ Pract, 2015; 6: 65-75. http://dx.doi:10.2147/AMEP.S69304

Barman MP, Hazarika J, Kalita A. Reliability, and validity of Assamese version of EORTC QLQ-C30 questionnaire for studying the quality of life of cancer patients of Assam. World Appl Sci J 2012; 17: 672-678.

http://citeseerx.ist.psu.edu/viewdoc/download?doi=10.1.1.390.676\&rep=re p1\&type $=$ pdf

Bratti M, Staffolani S. Student time allocation and educational production functions. Ann Econ Stat, 2002; 111: 103-140. http://dx.doi.org/10.2307/23646328

Chiu LK, Ishak NA, Mahat NI, Rashid B. Examining demographic and psychographic profiles of potential first-class undergraduates. Rev Eu Stud, 2015; 7: 253-264. http://dx.doi.org/ $10.5539 /$ res.v7n 3 p 253

Considine G, Zappalà G. The influence of social and economic disadvantage in the academic performance of school students in Australia. J Sociol, 2002; 38: 129-148. http://dx.doi:10.1177/ 144078302128756543

De Grave WS, Schmidt HG, Boshuizen HP. Effects of problembased discussion on studying a subsequent text: A randomized trial among first year medical students. Instr Sci, 2001; 29: 33-44. http://dx.doi:10.1023/A:1026571615672

Farooq MS, Chaudhry AH, Shafiq M, Berhanu G. Factors affecting students' quality of academic performance: a case of secondary school level. J Qual Tech Manag, 2011; 7: 1-14. http://pu.edu.pk/images/journal/iqtm/PDF-FILES/01-Factor.pdf

Ferguson E, James D, Madeley L. Factors associated with success in medical school: systematic review of the literature. BMJ, 2002; 324: 952-957. http://dx.doi.org/10.1136/bmj.324.7343.952

Goddard RD. Relational networks, social trust, and norms: A social capital perspective on students' chances of academic success. Educ Eval Policy Anal, 2003; 25: 59-74.
Haque M, Rahman NIA, Majumder MAA, Rahman NIA., Haque SZ, Zulkifli Z, Lugova H, Musa R M, Alattraqchi AG. Future Health Care Professionals and Leaders of East Coast of Malaysia: Issues that Essentially Persuades in Their Quality of Life Beside Education. J Healthc Leadersh, 2016. (Under Peer Review)

Lacour M, Tissington LD. The effects of poverty on academic achievement. Educ Res Rev, 2011; 6: 522-527. http://www.academicjournals.org/article/article1379765941_Lacour\%20an $\mathrm{d} \% 20$ Tissington.pdf

Legault L, Green-Demers I, Pelletier L. Why do high school students lack motivation in the classroom? Toward an understanding of academic amotivation and the role of social support. J Educ Psychol, 2006; 98: 567. http://dx.doi:10.1037/0022-0663.98.3.567

McMillan J, Western J. Measurement of the socio-economic status of Australian higher education students. High Educ, 2000; 39: 223 247. http://dx.doi:10.1023/A:1003943824357

Nourian A, Mousavinasab SN, Fehri A, Mohammadzadeh A, Mohammadi J. Evaluation of study skills and habits in medical students. South-East Asian J Med Educ, 2008; 2: 61-64. http://imsear.li.mahidol.ac.th/bitstream/123456789/165994/1/seajme2008v 2n1p61.pdf

Nunnally JC. 1978. Psychometric Theory. 2nd ed. New York, NY: McGraw-Hill.

Rippey RM, Thal S, Bongard SJ. A study of the University of Connecticut's criteria for admission into medical school. Med Educ, 1981; 15: 298-305. http://dx.doi:10.1111/j.1365-2923.1981.tb02492.x

Rubin KH, Coplan RJ, Bowker JC. Social Withdrawal in Childhood. Annu Rev Psychol, 2009; 60: 141-171. http://dx.doi:10.1146/annurev.psych.60.110707.163642

Salem RO, Al-Mously N, Nabil NM, Al-Zalabani AH, AlDhawi AF, Al-Hamdan N. Academic and socio-demographic factors influencing students' performance in a new Saudi medical school. Med Teach, 2013; 35: S83-S89. http://dx.doi:10.3109/0142159X.2013.765551

Schlee BM, Mullis AK, Shriner M. Parents social and resource capital: Predictors of academic achievement during early childhood. Child Youth Serv Rev, 2009; 31: 227-234. http://dx.doi.org/10.1016/j.childyouth.2008.07.014

\section{How to cite this article:}

Musa RM, Haque M. Academic Performance of Pre-Clinical and Clinical Medical Students' of East Coast Malaysian Peninsula: A Cross-Sectional and Descriptive Study That Stimuluses Their Life. J App Pharm Sci, 2017; 7 (06): 169-175. 